ARTIGO

\title{
Imagens de identidade profissional de futuros professores
}

\author{
Filomena Alves Rodrigues' \\ Maria João Mogarro'
}

\section{RESUMO}

Neste artigo problematiza-se a identidade profissional dos professores, com base na análise das reflexões finais de quatro mestrandos da Universidade de Lisboa, procurando-se compreender as concepções de identidade profissional desses futuros professores de ciências do ensino secundário. Nesta análise utiliza-se uma metodologia qualitativa centrada em uma perspectiva narrativa. Em suas reflexões, esses futuros professores referem a importância das aprendizagens que realizaram no âmbito da prática de ensino supervisionada e o seu contributo para o desenvolvimento profissional. Essas narrativas, escritas em primeira pessoa, expressam as percepções dos mestrandos sobre a própria evolução ao longo do processo de formação inicial e evidenciam suas identidades profissionais no final desse ciclo de formação. Essa evolução decorre de suas experiências letivas e não letivas e revela diferentes graus de consolidação das suas identidades profissionais.

\section{PALAVRAS-CHAVE}

formação inicial de professores; ensino superior; identidade profissional; prática de ensino supervisionada; narrativas.

'Universidade de Lisboa, Lisboa, Portugal.

Agradecimentos: Este trabalho de investigação foi financiado pela Fundação para

a Ciência e a Tecnologia (FCT), Portugal (referência SFRH/BD/111488/2015). 


\title{
PROFESSIONAL IDENTITY IMAGES OF FUTURE TEACHERS
}

\begin{abstract}
This article discusses the professional identity of teachers, based on the analysis of the final reflections of four masters students at the University of Lisbon, seeking to understand the conceptions of professional identity of these future teachers of secondary school science. This analysis uses a qualitative methodology focused on a narrative perspective. In their reflections, these future teachers refer to the importance of the learning that they made in the supervised teaching practice and their contribution to their professional development. These narratives, written in the first person, express the students' perceptions about their evolution during the initial training process and highlight their professional identities at the end of this training cycle. This evolution stems from their teaching and non-teaching experiences and reveals different degrees of consolidation of their professional identities.
\end{abstract}

KEYWORDS

initial teacher education; higher education; professional identity; supervised teaching practice; narratives.

\section{IMÁGENES DE IDENTIDAD PROFESIONAL DE FUTUROS PROFESORES}

\section{RESUMEN}

Este artículo aborda la identidad profesional de los docentes, basada en el análisis de las reflexiones finales de cuatro estudiantes de maestría de la Universidad de Lisboa, que buscan comprender las concepciones de identidad profesional de estos futuros docentes de ciencias de la escuela secundaria. Este análisis utiliza una metodología cualitativa centrada en una perspectiva narrativa. En sus reflexiones, estos futuros maestros se refieren a la importancia del aprendizaje que hicieron en la práctica docente supervisada y su contribución a su desarrollo profesional. Estas narraciones, escritas en primera persona, expresan las percepciones de los estudiantes sobre su evolución durante el proceso de capacitación inicial y resaltan sus identidades profesionales al final de este ciclo de capacitación. Esta evolución surge de sus experiencias docentes y no docentes y revela diferentes grados de consolidación de sus identidades profesionales.

\section{PALABRAS CLAVE}

formación inicial del profesorado; enseñanza superior; identidad profesional; práctica docente supervisada; narrativas. 


\section{INTRODUÇÃO}

A investigação recente na área da formação de professores tem destacado a importância da identidade profissional (Beauchamp e Thomas, 2009; Flores, 2015; Pillen, Beijaard e Brok, 2013), que consideramos configurar-se de forma significativa na fase inicial do processo de formação. De fato, a formação inicial de professores contribui para a construção de uma identidade profissional, que é determinada por um conjunto de fatores internos (motivação e emoções) e externos (contexto e experiências anteriores) (Izadinia, 2013). A formação inicial de professores é também um lugar importante para a promoção da reflexão e do desenvolvimento profissional (Alves e Flores, 2011). Procurando contribuir para o debate educacional sobre essa temática, neste trabalho de pesquisa analisam-se os relatórios da prática de ensino supervisionada de quatro mestrandos da Universidade de Lisboa, procurando-se compreender as concepções de identidade profissional desses futuros professores de ciências do ensino secundário. Destaca-se, assim, a pertinência deste trabalho para o desenvolvimento do conhecimento científico na área da formação de professores.

A questão de investigação que orientou esta pesquisa foi a seguinte: Como os futuros professores percecionam sua identidade profissional a partir da reflexão sobre a prática de ensino supervisionada? Para se responder a essa indagação, analisaram-se aquelas que foram as concepções dos participantes acerca das principais aprendizagens que resultaram dessa mesma prática e as questões que pensam ter contribuído para o seu desenvolvimento profissional, utilizando preferencialmente os relatórios finais da prática de ensino supervisionada, em particular a reflexão pessoal que os mestrandos neles devem desenvolver sobre a sua prática profissional.

Importa ainda referir que, neste trabalho, opta-se por se considerar que todos os indivíduos que ainda não estão formalmente habilitados para a docência e que frequentam um curso de formação inicial de professores, independentemente de já terem alguma experiência prévia como docentes (ou não), são considerados futuros professores. Eles passam a ser professores quando obtêm o seu diploma de mestrado em ensino, após a defesa e a aprovação do relatório final de prática de ensino supervisionada, que lhes confere habilitação própria para o exercício da profissão docente. Os participantes deste estudo frequentaram, nos anos letivos de 2014/2015 e 2015/2016, um dos seguintes mestrados da Universidade de Lisboa: mestrado em ensino de biologia e geologia ou mestrado em ensino de física e química.

\section{CONSTITUIÇÃO DA IDENTIDADE PROFISSIONAL DOS FUTUROS PROFESSORES}

Sendo objeto de estudo em várias áreas do conhecimento, tais como a educação, a psicologia, a sociologia e a antropologia, a definição de identidade profissional não é consensual. Contudo, vários autores afirmam que "a formação de um professor implica a construção de uma identidade profissional" (Rodrigues e Mogarro, 2018, p. 1.425). Resultando de um processo de construção, que é social, dinâmico e permanente, a constituição da identidade profissional implica a (re)interpretação individual de valores e experiências pessoais (Flores e Day, 2006). Como fenômeno relacional e emocional que é, essa identidade influencia a definição de objetivos e o desenvolvimento profissional (Izadinia, 2013; Stenberg et al., 2014). 
De acordo com Day et al. (2006), alguns autores consideram que a identidade profissional é estável (a partir de um determinado momento da carreira docente), sendo sustentada por um conjunto de valores, crenças e práticas. Outros autores consideram que ela é instável (Beauchamp e Thomas, 2010; Cooper e Olson, 1996), podendo a sua estabilidade temporária ser afetada por diversos fatores (biográficos e contextuais). Assim, não sendo fixa, nem imposta, a identidade profissional é dinâmica, idiossincrática e multifacetada, caracterizando-se por ser um constructo complexo que corresponde a um sentido de Eu (Chong, 2011; Flores, 2015; Ponte e Chapman, 2008). A identidade profissional tem três dimensões:

- uma dimensão narrativa, dado que se materializa sob a forma de histórias que as pessoas contam a si próprias e aos outros (Melville, Bartley e Fazio, 2013);

- uma dimensão intrapessoal, que se desenvolve a partir da reflexão e se refere à percepção que o indivíduo tem de si próprio no contexto profissional; e

- uma dimensão interpessoal, que se relaciona com o desenvolvimento, no âmbito da prática profissional, de competências e interiorização de normas, valores e cultura próprias da profissão (Sutherland e Markauskaite, 2012).

A forma como os futuros professores se sentem em diferentes momentos e as suas percepções, relativamente ao ensino, influenciam o desenvolvimento da sua identidade profissional (Chong e Low, 2009). Esses fatores estão permanentemente a ser (re)negociados a partir da experiência, pelo que a construção da identidade profissional dos futuros professores se constitui, muitas vezes, como uma luta interior relacionada com a confrontação, atribuição de significado e compreensão de perspectivas, expectativas e papéis concorrentes aos quais se têm de adaptar (Beijaard, Meijer e Verloop, 2004). Dessa forma, a identidade profissional pode ser vista como um dispositivo organizador de experiências que influência e é influenciada pela prática (MacLure, 1993). Contudo, Coward et al. (2015) advertem que nem todos os futuros professores modificam a sua identidade profissional ao longo da formação inicial de professores.

A identidade profissional constitui-se, assim, como uma conceptualização, consciente ou inconsciente, que os professores têm de si próprios em determinado contexto, situada na interseção de motivações pessoais, pedagógicas e políticas, a partir da reflexão acerca disso (Izadinia, 2013). A constituição da identidade profissional como um processo narrativo de autoconhecimento, resultante de um trabalho contínuo de compreensão, interpretação e reinterpretação da experiência e do próprio relativamente aos outros também é sublinhada por diversos autores (McCulloch et al., 2013; Pinho e Andrade, 2014). Estamos, assim, perante os discursos que permitem que os futuros professores incorporem suas ideologias pessoais na sala de aula, em estreita conexão com o desenvolvimento do seu Eu profissional (Aveling, Gillespie e Cornish, 2015). Desse modo, é na zona de fronteira dos diferentes discursos (pessoais, profissionais, sociais, imaginários e reais) que eles constroem a sua identidade profissional (Alsup, 2013), por meio de um processo transformador baseado na integração dos discursos no Eu pro- 
fissional. Para além disso, a narração promove o processo de autoconhecimento, permitindo atribuir sentido às experiências (Mogarro, 2005; Pinho e Andrade, 2014; Rodgers e Scott, 2008). A identidade profissional é assim construída a partir da interligação de diversas perspectivas, sendo influenciada pela multiplicidade de experiências vividas pelos indivíduos (Alsup, 2013) e expressando-se em seus discursos. As tensões que se estabelecem entre conhecimento pessoal (histórias de vida e memórias) e modelos racionalistas de construção de conhecimento (Cooper e Olson, 1996; Day et al., 2006) constituem-se como um dos problemas fundamentais da identidade profissional.

\section{NARRATIVAS COMO FORMA DE EXPRESSÃO IDENTITÁRIA}

A narrativa é uma forma dialética de expressão humana na qual as memórias e a imaginação se fundem, permitindo a (re)construção do Eu e a exploração de crenças e concepções dos futuros professores (Bruner, 2002). Como sublinham Schultz e Ravitch (2013), as narrativas permitem a compreensão dos processos complexos inerentes ao aprender a ensinar. Segundo Pinho e Andrade (2014), se a formação inicial de professores for baseada em estratégias narrativas, pode contribuir para aumentar a autopercepção, que é crucial para a aprendizagem e a construção da identidade profissional.

Uma vez que a dimensão narrativa da identidade permite o reconhecimento das dimensões agenciais e dinâmicas dessa característica, é reconhecida a importância do uso de narrativas na investigação sobre a identidade profissional dos professores. As histórias contadas pelos indivíduos constituem-se como expressões de valores, normas e estruturas culturais, que são escolhidas e geridas pelos indivíduos que as contam (Beauchamp e Thomas, 2009). Essas histórias, socialmente construídas e contadas, constituem a identidade nuclear dos professores (Gee, 2000).

A linguagem textual e oral tem, assim, um lugar central para o conhecimento de crenças e concepções dos futuros professores, pois proporciona oportunidades de reflexão sobre situações educativas que tenham sido significativas para os sujeitos (Galvão, 2005; Luwisch, 2002). Por isso, as narrativas, como forma pessoal de expressão, permitem a "compreensão dos discursos produzidos pelos atores educativos no interior do espaço social que ocupam” (Mogarro, 2005, p. 11), assumindo-se como formas de reflexão, de afirmação e transformação do Eu e de expressão do profissionalismo do narrador (Moreira, 2015).

\section{REFLEXÃO: CONTRIBUTOS PARA A CONSTITUIÇÃO DA IDENTIDADE PROFISSIONAL}

Diversos autores (Day et al., 2006; Löfström e Poom-Valickis, 2013) referem que a importância que os futuros professores atribuem ao seu trabalho depende da reflexão que fazem acerca dele, das suas emoções e do significado que atribuem às suas experiências anteriores (identidades passadas) relativamente às atuais (identidades presentes). De acordo com Izadinia (2013), as experiências anteriores, os modelos profissionais e as experiências prévias de ensino são os fatores mais importantes para a formação da imagem do Eu como professor. Na perspectiva de Chong e Low (2009) e 
Chong (2011), as crenças e as percepções dos futuros professores — sobre si próprios enquanto profissionais e sobre o tipo de professor que aspiram ser — têm um papel central na forma como eles interpretam e agem perante os novos conhecimentos que adquirem ao longo da formação inicial de professores. As percepções acerca do ensino e da profissão docente e as atitudes dos futuros professores alteram-se (positiva e negativamente) durante a prática de ensino supervisionada, de acordo com diferentes aspectos e situações inerentes à profissão docente.

Korthagen (2017) afirma que a maior parte das decisões que os professores tomam em sala de aula são inconscientes, sendo o seu comportamento apenas parcialmente influenciado pelo que aprenderam durante a formação inicial de professores. Esse autor refere ainda que a maior parte dos professores (sejam eles principiantes ou mais experientes) não têm, muitas vezes, consciência dos seus comportamentos (nem das razões que motivaram esses mesmos comportamentos). A reflexão, ou pensamento reflexivo, segundo Dewey, é um processo de construção de significado, alicerçado no inquérito científico (scientific inquiry), que envolve um pensamento sistemático, rigoroso e disciplinado e permite a compreensão de relações e a criação de conexões entre experiência e ideias (Rodgers, 2002). Por sua vez, Nóvoa (2013, p. 33) considera que a reflexão deve ser concebida como uma sequência de ideias e pensamentos que decorrem do exercício profissional e que têm consequências práticas. A reflexão compreende, assim, a capacidade que um indivíduo tem de pensar sobre si próprio, sobre as suas ações e sobre as situações que vivenciou, atribuindo-lhes significado (Kelchtermans, 2010; Stenberg, 2010). Assim, a prática reflexiva contribui fortemente para a construção da identidade profissional, constituindo-se como uma forma de questionar pressuposições e práticas docentes (Izadinia, 2013; Sutherland, Howard e Markauskaite, 2010).

De acordo com Schön (1983), a reflexão é um elemento indispensável para a aprendizagem e para o desenvolvimento profissionais, pois permite a consciencialização do conhecimento tácito e a transformação do saber-em-ação em conhecimento-em-ação (Oliveira-Formosinho, 2009; Rodgers e LaBoskey, 2016). A reflexão permite, assim, a compreensão das situações educativas, uma tomada de decisão consciente e a aprendizagem profissional, uma vez que é por meio desse processo que os futuros professores examinam e integram os novos conhecimento e experiências em suas crenças (Anspal, Eisenschmidt e Löfström, 2012; Kelchtermans, 2010).

Dewey (1997) e Schön (1983) mostram que a reflexão permite melhorar o processo de desenvolvimento profissional e, consequentemente, a qualidade do ensino. É também uma maneira de os futuros professores conhecerem a si mesmos e à sua prática durante a formação inicial de professores, uma vez que, nas suas reflexões, analisam de que modo suas crenças e valores são transferidos para sua prática profissional à medida que se vão desenvolvendo enquanto professores e começando a considerar as suas identidades profissionais (Beauchamp e Thomas, 2010). A maior parte da reflexão realizada pelos futuros professores envolve um pensamento retrospectivo sobre sua prática ou sobre suas ações — reflexão retrospectiva (dependente da memória). À medida que vão progredindo, os futuros professores poderão também começar a refletir durante a prática — reflexão em ação (reflection-in-action de Schön, 1983). Segundo Beauchamp e Thomas (2010), as reflexões 
sobre o futuro - reflexões antecipatórias (dependentes da imaginação) — também são importantes, pois podem auxiliar os futuros professores a anteciparem ações futuras e a evoluírem de modo que se aproximem de sua concepção de professor ideal, pelo fato de estarem cientes das características que ainda precisam de melhorar e desenvolver. Esse tipo de reflexão permite que os futuros professores olhem para além das fronteiras da sua formação inicial, permitindo-lhes prever uma identidade futura. Olhar para o futuro pode estimular o pensamento (auto)crítico, produzindo um sentido de agência que lhes permitirá alcançar os seus objetivos estabelecendo a relação entre suas reflexões, sua identidade e seu Eu ideal (ideal teacher self).

Korthagen e Wubbels (2001) propõem um modelo de reflexão (ALACT model) que se foca não só nos aspectos racionais dos papéis profissionais (ação propriamente dita), mas também nos aspectos emocionais e motivacionais da ação profissional (pensar sobre a ação e tomar consciência dela) e na sua influência para a criação de formas alternativas de ação. Mais tarde, Korthagen (2004) desenvolveu o modelo cebola, que mostra os níveis de mudança individual, entre os quais podem existir relações (os níveis mais exteriores podem influenciar os mais interiores e vice-versa). De acordo com o autor, esses níveis de reflexão vão-se desenvolvendo e alinhando ao longo da vida profissional do professor. A reflexão sobre as qualidades nucleares promove o desenvolvimento profissional, procurando relacionar os aspectos pessoais e profissionais, a partir das qualidades e dos ideais nucleares dos sujeitos (Korthagen, 2016).

Perspectivando a reflexão de um outro modo, Ward e McCotter (2004) propõem quatro tipos de reflexão:

1. descritiva;

2. técnica;

3. dialógica; e

4. transformadora.

A primeira foca-se em preocupações autocentradas, não apresentando quaisquer contribuições para a prática profissional futura. A segunda centra-se em situações específicas e preocupa-se em apresentar uma resolução do problema ou situação identificada, contudo também não identifica mudanças na prática. $\mathrm{O}$ foco da reflexão dialógica são os alunos, reconhecendo limitações, potencialidades e formas de melhorar a prática profissional futura. O quarto tipo de reflexão, a transformadora, revela um envolvimento pessoal nesse processo, fazendo referência a mudanças na prática profissional.

\section{FORMAÇÃO PROFISSIONAL: ENQUADRAMENTO LEGISLATIVO DOS MESTRADOS EM ENSINO}

Em Portugal, de acordo com o decreto-lei n. 79/2014, a habilitação para a docência no ensino secundário está subordinada à conclusão de um mestrado em ensino, sendo necessário o domínio do conteúdo científico e pedagógico das áreas disciplinares que serão lecionadas e das metodologias de investigação educacional. Esse documento revogou o anterior, tornando-se ainda mais prescritivo dado que identifica as áreas de formação específicas que devem ser contempladas nos mes- 
trados em ensino. Contudo, no âmbito deste trabalho, remetemos para a legislação anterior, dado que é nesta que se enquadram o mestrado em ensino de biologia e geologia e o mestrado em ensino de física e química no interior dos quais foram produzidos os discursos em análise. Assim, de acordo com a legislação que estava em vigor (decreto-lei n. 43/2007), os mestrados em ensino deviam promover a articulação teoria/prática, estimular a inovação, a reflexão e a investigação e fomentar a aprendizagem ao longo da vida em seus quatro componentes de formação:

1. formação na área de docência;

2. formação educacional geral;

3. didáticas específicas; e

4. prática de ensino supervisionada.

Os referidos mestrados em ensino (mestrado em ensino de biologia e geologia e o mestrado em ensino de física e química) têm a duração de dois anos (quatro semestres). Nesses mestrados, a prática de ensino supervisionada desdobra-se em quatro unidades curriculares de Iniciação à Prática Profissional. Contudo, apenas no segundo ano, na Iniciação à Prática Profissional III e IV, os candidatos a professor têm oportunidade de intervir em sala de aula (Rodrigues e Mogarro, 2015, 2018). No âmbito da Iniciação à Prática Profissional IV, os candidatos a professor têm de planificar e implementar uma unidade didática, que é norteada por um problema de investigação. E no final da Iniciação à Prática Profissional IV os mestrandos têm de escrever, apresentar e defender publicamente um relatório final da prática de ensino supervisionada, no qual explicitam os fundamentos científicos, pedagógicos e metodológicos que nortearam a construção da unidade didática que implementaram em sala de aula no âmbito dessa unidade curricular. Nesse relatório, os futuros professores têm ainda de incluir uma reflexão pessoal sobre a sua prática profissional, a qual constitui um discurso narrativo pessoal de grande importância para se compreender o modo como os futuros professores expressam a sua identidade e os significados que atribuem à sua experiência de formação inicial.

\section{METODOLOGIA}

Utilizando uma metodologia qualitativa centrada em uma perspectiva narrativa, analisou-se parte dos relatórios da prática de ensino supervisionada de quatro mestrandos da Universidade de Lisboa para responder à questão de investigação anteriormente formulada. Esses relatórios de caráter investigativo estão geralmente estruturados em cinco partes principais:

1. o enquadramento teórico: que inclui a explicitação do(s) método(s) de ensino-aprendizagem escolhido(s) para a unidade didática lecionada pelo autor de cada relatório;

2. a proposta didática: que contempla a fundamentação científica e didática da unidade didática lecionada;

3. a metodologia: que compreende a explicação da problemática que norteou a construção daquela unidade didática e todos os procedimentos metodológicos utilizados para a recolha e análise dos dados; 
4. a apresentação e discussão dos resultados; e

5. as conclusões e a reflexão final.

Nesses relatórios são ainda incluídos, como anexo, todos os materiais que foram sendo construídos pelos mestrandos, nomeadamente planos de aula e materiais utilizados nas aulas (por exemplo, fichas de trabalho). A reflexão pessoal (escrita de forma livre) que é incluída no final do relatório retrata, na primeira pessoa, as questões mais marcantes da experiência vivida na Iniciação à Prática Profissional III e IV. Foi sobre essas reflexões que recaiu a nossa análise, uma vez que elas evidenciam as aprendizagens dos candidatos a professor e a importância que eles atribuem à prática de ensino supervisionada para o seu desenvolvimento profissional. Os relatórios, que continham essas reflexões finais dos futuros professores, foram entregues e defendidos durante o ano de 2016. Dado o reduzido número de mestrandos inscritos no mestrado em ensino de biologia e geologia e no mestrado em ensino de física e química, todos os participantes que exprimiram o seu interesse e consentimento informado, concordando em fazer parte desta investigação, foram selecionados. A pesquisa seguiu os procedimentos éticos definidos e aprovados pela Comissão de Ética do Instituto de Educação da Universidade de Lisboa, que aprovou este projeto de investigação.

\section{QUADRO DE ANÁLISE}

A análise qualitativa de conteúdo dos dados recolhidos foi efetuada com o auxílio do programa informático Excel, tendo sido previamente definido um quadro de análise indutivo, cujas categorias e subcategorias emergiram com base na leitura das reflexões escritas pelos mestrandos. No Quadro 1 estão identificadas as subcategorias definidas.

A categoria prática profissional compreende a prática de ensino supervisionada inserida no contexto do programa de formação inicial de professores. Nela incluem-se três subcategorias:

1. aprendizagens, referente àquilo que os mestrandos consideram ter aprendido no contexto da sua prática de ensino supervisionada;

Quadro 1 - Codificação das reflexões finais.

\begin{tabular}{|c|c|}
\hline Categorias & Subcategorias \\
\hline \multirow{2}{*}{ Prática profissional } & Aprendizagens \\
\cline { 2 - 2 } & Relação com os alunos \\
\cline { 2 - 2 } & Dificuldades, desafios e condicionantes \\
\hline \multirow{2}{*}{ Identidade profissional } & Competências do professor \\
\cline { 2 - 2 } & Desenvolvimento profissional \\
\cline { 2 - 2 } & Perspectivas para o futuro \\
\hline
\end{tabular}

Fonte: Banco de dados da pesquisa.

Elaboração das autoras. 
2. relação com os alunos, que diz respeito às partes da reflexão em que os mestrandos expressam, de diferentes formas, de que modo os professores influenciam os alunos e como os alunos influenciam a prática profissional dos professores; e

3. dificuldades, desafios e condicionantes, subcategoria relativa aos momentos da reflexão em que os futuros professores se referem a dificuldades, desafios, obstáculos e condicionantes com que se depararam durante a prática de ensino supervisionada.

A categoria identidade profissional compreende as partes das narrativas dos candidatos a professor que permitem caracterizar a (re)construção da sua identidade profissional por influência da prática de ensino supervisionada inserida no contexto do programa de formação inicial. Compreende três subcategorias:

1. competências do professor, referente às competências que os mestrandos indicam como essenciais para um professor poder desempenhar bem a sua profissão;

2. desenvolvimento profissional, referente àquilo que os futuros professores consideram ter contribuído para o seu desenvolvimento profissional no decurso da sua prática de ensino supervisionada e ao reconhecimento dos aspectos que ainda necessitam ser melhorados; e

3. perspectivas para o futuro, refere-se à antevisão que os candidatos a professor fazem da sua prática futura.

No processo de análise, mais concretamente durante a fase de categorização, seguiu-se o modelo de análise de Schreier (2012), cumprindo-se a regra da exclusividade mútua. A análise das narrativas em sua globalidade permitiu ainda compreender as perspectivas assumidas pelos mestrandos e o tipo de reflexão que escreveram, de acordo com os pontos de vista de Beauchamp e Thomas (2010) e Ward e McCotter (2004), aqui descritos anteriormente. Importa ainda referir que, uma vez que este trabalho resulta de uma investigação de dimensão mais vasta, neste texto são apenas apresentados alguns resultados da análise das reflexões finais dos mestrandos.

\section{CARACTERIZAÇÃO DOS PARTICIPANTES}

São analisados os discursos de quatro participantes no estudo, duas mestrandas e dois mestrandos, que apresentam os seguintes perfis:

- Maria era licenciada em biologia e não possuía qualquer experiência de docência; à data da recolha de dados, essa participante tinha 23 anos;

- Com 36 anos, Joana era licenciada em química; essa mestranda já tinha experiência docente, pois dava aulas particulares em centros de explicações;

- Também licenciado em química e com 41 anos, Nuno já tinha, à data da recolha de dados, experiência prévia de docência no ensino básico;

- Rafael era doutorado em física e tinha 44 anos; esse participante já tinha experiência prévia de docência nos ensinos básico e superior. 


\section{REFLEXÕES: DIMENSÕES PREDOMINANTES}

A reflexão de Maria, participante que não tinha qualquer experiência profissional, apesar de não ter um foco muito evidente, centra-se mais na relação com os alunos. Por sua vez, a reflexão de Joana, apesar de se centrar em seu desenvolvimento profissional (como se pode constatar pelo gráfico da Figura 1), está primordialmente focada em suas aprendizagens enquanto futura professora. A análise das reflexões de Nuno e Rafael, participantes que já tinham alguma experiência profissional no âmbito da docência, mostra que estas são já muito centradas no desenvolvimento profissional (Figura 1). A análise dos dados evidencia, assim, que as dimensões predominantes nas reflexões dos mestrandos se relacionam com as aprendizagens que estes realizaram no âmbito da prática de ensino supervisionada e com as suas formas de desenvolvimento profissional, que, por sua vez, contribuem para a constituição das identidades profissionais dos participantes. Será, por isso, nessas duas dimensões que se centra a nossa análise.

Os quatro mestrandos destacaram as seguintes aprendizagens e competências desenvolvidas no âmbito da prática de ensino supervisionada:

- o conhecimento de diferentes tipos de tarefas;

- a seleção e implementação de tarefas;

- a compreensão da importância de momentos de revisão e síntese;

- os processos de promoção de discussões coletivas;

- a reformulação do processo de ensino/aprendizagem;

- as práticas de investigação (da própria prática profissional);

- os procedimentos de construção de tarefas;

- a valorização da reflexão e formas adequadas de a realizar;

Figura 1 - Foco das reflexões de cada um dos participantes de acordo com o número de unidades de registo.

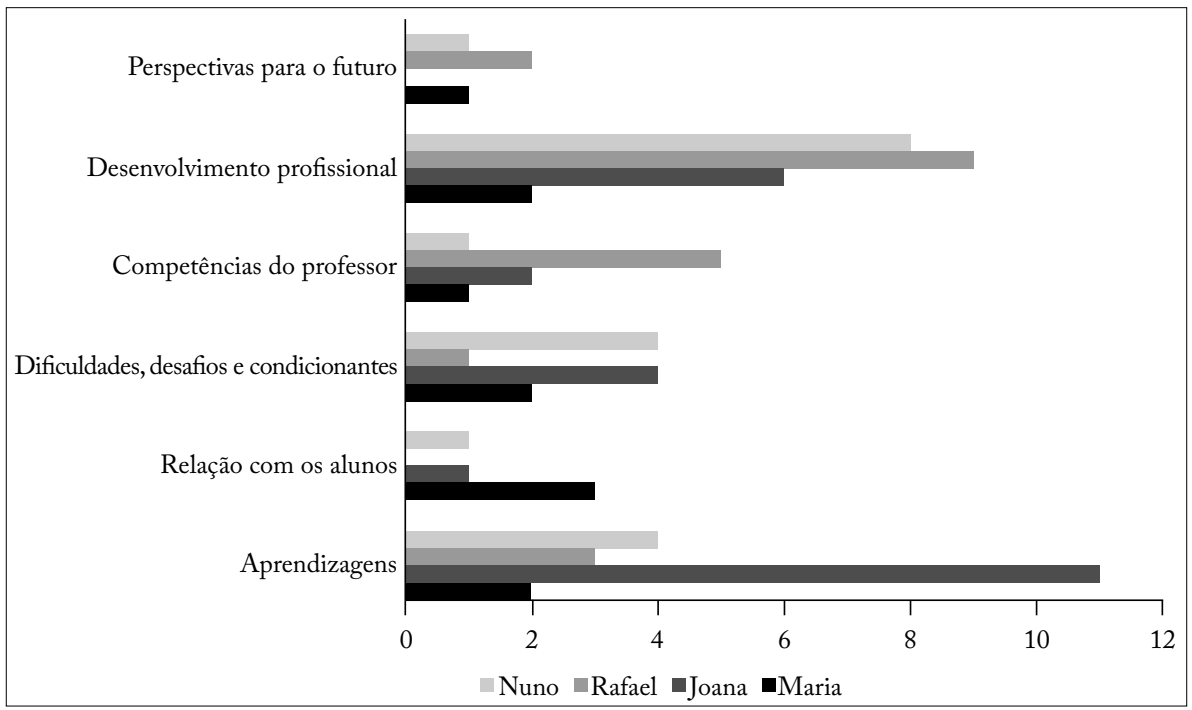

Elaboração das autoras. 
- a importância do trabalho colaborativo;

- a dinamização de ambientes de aprendizagem;

- a importância do contexto social da profissão;

- a importância dos conhecimentos científicos e didáticos;

- o conhecimento de elementos e processos de avaliação; e

- a gestão de comportamentos em espaços exteriores.

Destas, importa destacar as aprendizagens relacionadas com a dinamização de ambientes de aprendizagem, que são referidas por três dos participantes (Maria, Joana e Rafael), uma vez que nenhuma das restantes aprendizagens é comum a mais do que um participante.

Relativamente ao seu desenvolvimento profissional, as reflexões dos mestrandos mostram que eles:

- superaram as dificuldades que sentiram;

- percepcionaram as suas dinâmicas de sala de aula;

- reconstruíram as suas concepções profissionais;

- passaram a gerir objetivos e discussões coletivas;

- atribuíram importância ao processo supervisionado, à autoavaliação e aos contributos da (auto)investigação;

- desenvolveram competências; e

- aprenderam a estabelecer relações com a teoria.

Contudo, os aspectos que são destacados por mais do que um mestrando são:

- a reconstrução de concepções profissionais;

- a importância da aprendizagem ao longo da vida;

- o desenvolvimento de competências; e

- os contributos da investigação.

As reflexões dos participantes evidenciam, na primeira pessoa, a identidade profissional de cada mestrando, focando-se naquelas que eles consideraram ser as aprendizagens mais importantes que realizaram durante a prática de ensino supervisionada.

Assumindo uma perspectiva retrospectiva, centrada nas especificidades da sua própria aprendizagem, a reflexão de Joana explicita as transformações que o seu Eu sofreu a partir do contato com a prática:

Saio daqui com um outro eu: um eu que aprendeu a construir tarefas desafiantes para os seus alunos e a realizá-las na sala de aula; um eu que aprendeu a dar importância às dificuldades e aprendizagens dos seus alunos; um eu que aprendeu a refletir sobre a sua prática; um eu que passou a ter consciência da importância do trabalho colaborativo nas escolas [...]; um eu que aprendeu o que é a investigação em educação e como se pode colocá-la em prática; e, por último, um eu que passou a olhar de outro modo para a sala de aula e para os seus alunos. (Relatório de Joana, p. 124) 
As reflexões de Maria e de Rafael demonstram a importância que esses mestrandos atribuem às aprendizagens dos alunos e à sua própria aprendizagem. Essas reflexões assumem, simultaneamente, uma perspectiva retrospectiva e antecipatória, estando a primeira associada às aprendizagens dos alunos e a segunda relacionada com a aprendizagem ao longo da vida:

Para mim foi um ano cheio e em cheio! Ser professor é isto, é focar-nos nos nossos alunos e preparar as nossas aulas pensando neles, é continuar a apostar na nossa formação em prol de melhorarmos as nossas aulas, é querer sempre fazer melhor! (Relatório de Maria, p. 127)

Fazendo um esforço de reflexão para identificar três [aprendizagens] que considero mais significativas [...] poderei talvez indicar as seguintes: que cada aluno é diferente e tem capacidades que o professor pode ajudar a desenvolver criando ambientes de aprendizagem adequados; que a melhoria do desempenho da profissão docente é resultado de uma construção social que, tal como as aprendizagens dos alunos, requer um desenvolvimento pessoal contínuo tanto através do estudo pessoal como através da interação com pares mais experimentados; e que um conhecimento profundo dos modelos e teorias científicas que enquadram os conteúdos curriculares, tem de fundamentar qualquer boa prática pedagógica. (Relatório de Rafael, p. 149)

Também centrada na aprendizagem profissional e dos alunos, a reflexão de Nuno revela uma perspectiva antecipatória centrada em seu desenvolvimento profissional futuro:

Assim, o meu desenvolvimento profissional passará, cada vez mais, por pôr o foco no aluno, devendo fazer uma análise aturada sobre os processos do seu desenvolvimento cognitivo e as melhores formas de impulsionar as suas aprendizagens. (Relatório de Nuno, p. 112)

[...] poderei recorrer à metodologia de investigação usada neste trabalho, sempre que ache que, em vez de parar, necessito de rever, analisar e melhorar a forma como desenvolvo a minha prática profissional. É um caminho de futuro, que começa hoje. (Relatório de Nuno, p. 113)

Importa também realçar os diferentes tipos de reflexões que encontramos neste conjunto de discursos dos mestrandos sobre a sua prática de ensino supervisionada. Essa caracterização permite compreender algumas das dimensões fundamentais que os futuros professores atribuem ao seu trabalho nessa fase de contato com a realidade escolar, assim como a diversidade de abordagens que eles protagonizam, em virtude de terem ou não experiências profissionais prévias nesses contextos.

A análise da reflexão de Maria mostra que esta é predominantemente descritiva, autocentrada e sem qualquer referência a contribuições para a sua prática futura: 
O primeiro grande desafio foi escolher a temática da minha investigação, procurando, por um lado, integrar as novas tecnologias no ensino da Biologia e Geologia e, por outro lado, promover a discussão acerca de alguns dos aspectos da Natureza da Ciência. (Relatório de Maria, p. 126)

Depois das visitas de estudo tive oportunidade de participar numa sessão de formação de professores sobre dinâmicas de grupo. Esta foi, sem qualquer dúvida, muito enriquecedora para mim. (Relatório de Maria, p. 127)

Em sua reflexão, de caráter técnico, Joana refere-se a situações específicas da sua prática letiva. Para além disso, a mestranda apresenta problemas e indica de que forma ocorreu a sua resolução:

O fato de os alunos não estarem familiarizados com esta nova dinâmica de sala de aula, em que assumem um papel ativo na sua aprendizagem e que o papel da professora passa a ser de orientadora, fez com que numa fase inicial, solicitassem com muita frequência a minha orientação, o que por vezes foi difícil de gerir. No entanto, esta dificuldade foi se tornando cada vez menor. (Relatório de Joana, p. 122)

Assumindo uma postura eminentemente dialógica, Rafael reflete, pensando de que forma pode melhorar o ambiente de aprendizagem dos seus alunos, fazendo referência a limitações, potencialidades e formas de melhorar a sua própria prática:

Quais os aspectos em que notei uma maior necessidade de desenvolvimento pessoal e profissional? [...] Uma melhor percepção das dinâmicas da aula, que permita perceber mais rapidamente o envolvimento de cada aluno nas tarefas e as necessidades específicas de cada um. [...] Em terceiro lugar, uma gestão mais eficaz das discussões coletivas, sabendo aproveitar e estimular as contribuições de cada aluno [...]. (Relatório de Rafael, p. 148)

A reflexão de Nuno demonstra o seu envolvimento pessoal nas situações de aprendizagem. Em sua narrativa, esse participante propõe transformações para a sua prática:

Todos os aspectos teóricos foram sendo absorvidos e usados na prática, desde a construção das tarefas, à sua planificação, à construção dos elementos de avaliação e culminando na lecionação. De uma forma mais ampla, fiquei mais ciente do tipo e diversidade de tarefas a propor aos alunos, de acordo com as turmas a quem vou lecionar, fazendo uma análise do que pretendo alcançar, as competências que pretendo que os alunos desenvolvam, e aplicar diferentes estratégias consoante as suas caraterísticas e as situações de aprendizagem. (Relatório de Nuno, p. 112)

A análise efetuada às reflexões que foram escritas por esses quatro futuros professores demonstrou que eles tendem a destacar diferentes aspectos não só no que se refere às suas aprendizagens, como também ao seu desenvolvimento profissional. Todavia, existem algumas dimensões que são comuns à maioria, nomeadamente a 
referência a aprendizagens relacionadas com a dinamização de ambientes educacionais e a valorização dessas mesmas aprendizagens para o desenvolvimento de suas competências, assim como a importância da componente investigativa para uma aprendizagem ao longo da vida. Embora cada um o faça de forma própria e focando-se em questões distintas, as narrativas dos quatro mestrandos que participaram nesta investigação mostram que estes evoluíram e melhoraram os seus desempenhos, isto é, desenvolveram-se profissionalmente. Contudo, como se viu, ao contrário dos restantes participantes, Maria não foca tanto a sua reflexão em sua prática (presente ou futura), optando por descrever experiências não letivas que foram particularmente significativas para o seu desenvolvimento, nomeadamente a escolha da temática de investigação e a participação em uma sessão de formação. Por sua vez, Joana, Nuno e Rafael apresentam uma escrita mais centrada nos contributos das atividades letivas para o seu desenvolvimento profissional, demonstrando a reconstrução de suas percepções profissionais. Nesse sentido, Joana passou a reconhecer a relevância da reflexão, e Nuno e Rafael passaram a valorizar a individualidade do aluno. Importa ainda referir que os quatro futuros professores destacam, em suas reflexões, a importância da centralidade do aluno no processo de ensino-aprendizagem e a relevância do envolvimento em atividades de investigação para o seu desenvolvimento profissional.

A valorização de diferentes dimensões do desenvolvimento profissional revela ainda as características das identidades profissionais desses futuros professores, que apresentam alguns traços semelhantes, mas são fundamentalmente diferentes. Perspectivando-se a identidade profissional como um dispositivo organizador de experiências, os discursos dos participantes mostram que eles reconstruíram algumas de suas imagens profissionais. As narrativas de Maria e Joana revelam discursos bastante autocentrados, indiciando a existência de identidades profissionais ainda pouco consolidadas. No caso de Maria, seu discurso, embora muito focado nas experiências que contribuíram para o seu desenvolvimento profissional, demonstra a sua inexperiência e a necessidade que essa participante ainda tem no sentido de desenvolver a sua capacidade de reflexão escrita. No caso de Joana, estando centrada na tecnicidade do processo de ensino, sua reflexão revela uma identidade focada na execução dos seus papéis profissionais. Por sua vez, as narrativas de Nuno e Rafael centram-se no seu desenvolvimento profissional, revelando identidades profissionais mais consolidadas provavelmente em virtude da experiência docente que já possuíam. Dessas identidades emerge uma preocupação nuclear com a aprendizagem dos alunos. Nesse sentido, o discurso de Rafael foca-se na importância da criação de dinâmicas e ambientes de aprendizagem adequados, havendo ainda uma preocupação com o seu desenvolvimento pessoal e profissional. No caso de Nuno, sua reflexão expressa a valorização do desenvolvimento cognitivo dos alunos pela diversificação de estratégias de ensino que ele próprio promoveu.

\section{CONSIDERAÇÕES FINAIS}

Os relatórios finais da prática de ensino supervisionada são documentos acadêmicos destinados à obtenção de um título pós-graduado, que simultanea- 
mente confere habilitação para o exercício da profissão docente. Esses relatórios assumem uma centralidade significativa no percurso desses candidatos a professor, pois constituem dispositivos que afirmam a sua preparação profissional, as aquisições científicas e pedagógicas que realizaram, mas também suas emoções e seus valores, sua ética e suas referências, em um processo de reflexão sobre si, sobre seu trabalho e a construção de sua identidade, constituindo-se também como pontes de passagem, pois, quase ritualisticamente, estabelecem a relação entre o tempo da formação profissional dos autores e o tempo futuro da profissão, no qual eles depositam suas esperanças.

As reflexões analisadas constituem-se como narrativas na primeira pessoa que expressam a importância da prática e das aprendizagens realizadas nesse âmbito para o desenvolvimento de competências, isto é, espelham a evolução do desenvolvimento profissional dos futuros professores e a sua identidade profissional no final do mestrado em ensino que frequentaram. Essas aprendizagens estão relacionadas com a gestão de sala de aula e a dinamização de ambientes de aprendizagem, ou seja, prendem-se com a relação com os alunos e com a valorização da investigação como forma de desenvolvimento profissional.

As identidades dos participantes têm algumas dimensões comuns, mas são fundamentalmente diferentes, como foi demonstrado, parecendo estar relacionadas com as experiências profissionais prévias de cada um. Por um lado, os dois participantes com experiência de docência em instituições escolares, públicas e privadas, tendem a focar sua reflexão em seu desenvolvimento profissional. Por outro, as participantes sem experiência docente ou com prévias e pontuais funções de tutoria em centros de explicações valorizam em suas reflexões as relações que estabelecem com seus alunos, o que vários autores (por exemplo, Lindqvist et al., 2017) referem ser típico no início do exercício de funções docentes. Verifica-se ainda que os participantes que já tinham experiência na docência conseguem efetuar reflexões mais profundas, analisando mais detalhadamente a sua prática profissional, pensando em formas de a melhorar, isto é, apresentando reflexões dialógicas e transformadoras. Realçamos a importância da experiência na capacidade reflexiva dos participantes e dos investigadores educacionais em geral, assim como na problematização mais profunda das situações educativas. Confirmamos, também, o que já foi dito por vários autores (Estola, Uitto e Syrjälä, 2014; Flores, 2016), isto é, que a formação inicial de professores é apenas o início de um percurso de autoformação e desenvolvimento profissional que decorre ao longo da vida no contexto profissional, sendo acompanhado de uma permanente (re)construção da identidade profissional do professor. Importa ainda sublinhar que a originalidade desta investigação é conferida pela utilização das reflexões como formas narrativas de expressão identitária, em linha com os novos caminhos de pesquisa que indiciam a necessidade da realização de estudos que procurem compreender a influência da experiência docente prévia para a construção da identidade profissional de futuros professores e a valorização das narrativas pessoais como formas de expressão dessa identidade. 


\section{REFERÊNCIAS}

ALSUP, J. Teacher identity discourses: negotiating personal and professional spaces. Abingdon: Routledge, 2013.

ALVES, M. P.; FLORES, M. A. Trabalho docente, formação e avaliação: clarificar conceitos, fundamentar práticas. Mangualde: Edições Pedago, 2011.

ANSPAL, T.; EISENSCHMIDT, E.; LÖFSTRÖM, E. Finding myself as a teacher: exploring the shaping of teacher identities through student teachers' narratives. Teachers and Teaching: Theory and Practice, London, v. 18, n. 2, p. 197-216, Apr. 2012. https:// doi.org/10.1080/13540602.2012.632268

AVELING, E.; GILLESPIE, A.; CORNISH, F. A qualitative method for analysing multivoicedness. Qualitative Research, Thousand Oaks, v. 15, n. 6, p. 670-687, Dec. 2015. https://doi.org/10.1177/1468794114557991

BEAUCHAMP, C.; THOMAS, L. Understanding teacher identity: an overview of issues in the literature and implications for teacher education. Cambridge Journal of Education, London, v. 39, n. 2, p. 175-189, June 2009. https://doi. org/10.1080/03057640902902252

BEAUCHAMP, C.; THOMAS, L. Reflecting on an ideal: student teachers envision a future identity. Reflective Practice, United Kingdom, v. 11, n. 5, p. 631-643, 2010. https://doi.org/10.1080/14623943.2010.516975

BEIJAARD, D.; MEIJER, P. C.; VERLOOP, N. Reconsidering research on teacher's professional identity. Teaching and Teacher Education, London, v. 20, n. 2, p. 107-128, Feb. 2004. https://doi.org/10.1016/j.tate.2003.07.001

BRUNER,J.Making stories: law, literature, life. Nova York: Farrar, Straus and Giroux, 2002. CHONG, S. Development of teachers' professional identities: from pre-service to their first year as novice teachers. KEDI Journal of Educational Policy, Chungcheongbukdo, v. 8, n. 2, p. 219-233, 2011.

CHONG, S.; LOW, E. Why I want to teach and how I feel about teaching: Formation of teacher identity from pre-service to the beginning teacher phase. Educational Research for Policy and Practice, Dordrecht, v. 8, n. 59, Apr. 2009. https://doi. org/10.1007/s10671-008-9056-z

COOPER, K.; OLSON, M. R. The multiple "I's" of teacher identity. In: KOMPF, M.; BOND, W. R.; DWORET, D.; BOAK, R. T. (ed.). Changing research and practice: teachers' professionalism, identities and knowledge. London: The Falmer Press, 1996. p. 78-89.

COWARD, F. L.; HAMMAN, D.; JOHNSON, L.; LAMBERT, M.; INDIATSI, J.; ZHOU, L. Centrality of enactive experiences, framing, and motivation to student teachers' emerging professional identity. Teaching Education, London, v. 26, n. 2, p. 196-221, Jan. 2015. https://doi.org/10.1080/10476210.2014.996741

DAY,C.; KINGTON, A.; STOBART, G.; SAMMONS,P.The personal and professional selves of teachers: stable and unstable identities. British Educational Research Journal, London, v.32, n. 4, p. 601-616, Aug. 2006. https://doi.org/10.1080/01411920600775316 
DEWEY, J. How we think. New York: Dover, 1997.

ESTOLA, E.; UITTO, M.; SYRJÄLÄ, L. O processo narrativo de tornar-se professor: o caso finlandês. In: FLORES, M. A. (org.). Formação e desenvolvimento profissional de professores: contributos internacionais. Coimbra: Almedina, 2014. p. 105-128.

FLORES, M. A. Formação docente e identidade profissional: tensões e (des) continuidades. Educação, Porto Alegre, v. 38, n. 1, p. 138-146, jan./abr. 2015. http:// dx.doi.org/10.15448/1981-2582.2015.1.15973

FLORES, M. A. Teacher education curriculum. In: LOUGHRAN, J.; HAMILTON, M. L. (eds.). International handbook of teacher education. Heidelberg: Springer, 2016.v. 1, p. 187-230.

FLORES, M. A.; DAY, C. Contexts which shape and reshape new teachers' identities: a multi-perspective study. Teaching and teacher education, London, v. 22, n. 2, p. 219232, Feb. 2006. https://doi.org/10.1016/j.tate.2005.09.002

GALVÃO, C. Narrativas em educação. Ciência e Educação (Bauru), Bauru, v. 11, n. 2, p. 327-345, maio/ago. 2005.http://dx.doi.org/10.1590/S1516-73132005000200013 GEE, J. P. Identity as an analytic lens for research in education. Review of Research in Education, Thousand Oaks, v. 25, p. 99-125, Jan. 2000. http://dx.doi. org/10.2307/1167322

IZADINIA, M. A review of research on student teachers' professional identity. British Educational Research Journal, London, v. 39, n. 4, p. 694-713, Aug. 2013. https://doi. org/10.1080/01411926.2012.679614

KELCHTERMANS, G. Narratives and biography in teacher education. In: PETERSON, P.; BAKER, E.; MCGAW, B. (eds.). International encyclopedia of education. Oxford: Elsiever, 2010. v. 7, p. 610-614.

KORTHAGEN, F. A. J. In search of the essence of a good teacher: towards a more holistic approach in teacher education. Teacher and Teaching Education, London, v. 20, p. 77-97, Jan. 2004. https://doi.org/10.1016/j.tate.2003.10.002

KORTHAGEN, F. A. J. Pedagogy of teacher education. In: LOUGHRAN, J.; HAMILTON, M. L. (eds.). International handbook of teacher education. Nova York: Springer, 2016. v. 1, p. 311-346.

KORTHAGEN, F. A. J. Inconvenient truths about teacher learning: towards professional development 3.0. Teachers and Teaching: Theory and Practice, London, v. 23, n. 4, p. 387-405, 2017. https://doi.org/10.1080/13540602.2016.1211523

KORTHAGEN, F. A.J.; WUBBELS, T. Learning from practice. In: KORTHAGEN, F. A.J.; KESSELS,J.; KOSTER, B.; LAGERWERF, B.; WUBBELS, T.(eds.). Linking practice and theory: the pedagogy of realistic teacher education. Mahway: Routledge, 2001. p. 32-50.

LINDQVIST, H.; WEURLANDER, M.; WERNERSON, A.; THORNBERG, R. Resolving feelings of professional inadequacy: student teachers' coping with distressful situations. Teaching and Teacher Education, London, v. 64, p. 270-279, May 2017. https://doi.org/10.1016/j.tate.2017.02.019 
LÖFSTRÖM, E.; POOM-VALICKIS, K. Beliefs about teaching: persistent or malleable? A longitudinal study of prospective student teachers' beliefs. Teaching and Teacher Education, London, v. 35, p. 104-113, Oct. 2013. https://doi.org/10.1016/j. tate.2013.06.004

LUWISCH, F. E. O ensino e a identidade narrativa. Revista de Educação, Lisboa, v. 11, n. 2, p. 2-13, 2002.

MACLURE, M. Arguing for your self: identity as an organising principle in teachers' jobs and lives. British Educational Research Journal, London, v. 19, n. 4, p. 311-322, Sept. 1993. https://doi.org/10.1080/0141192930190401

MCCULLOCH, A.; MARSHALL, P. L.; DECUIR-GUNBY, J. T.; CALDWELL, T. Math autobiographies: a window into teachers' identities as Mathematics learners. Social Science and Mathematics, New Jersey, v. 113, n. 8, p. 380-389, Dec. 2013. https://doi.org/10.1111/ssm.12041

MELVILLE, W.; BARTLEY, A.; FAZIO, X. Scaffolding the inquiry continuum and the constitution of identity. International Journal of Science and Mathematics Education, Dordrecht, v. 11, n. 5, p. 1.255-1.273, Oct. 2013. https://doi.org/10.1007/ s10763-012-9375-7

MOGARRO, M. J. Memórias de professores: discursos orais sobre a formação e a profissão. História da Educação, [S.l], v. 17, p. 7-31, abr. 2005.

MOREIRA, M. A. A supervisão pedagógica como prática de transformação: o lugar das narrativas profissionais. Revista Eletrônica de Educação, São Carlos, v. 9, n. 3, p. 48-63, nov. 2015. http://dx.doi.org/10.14244/198271991380

NÓVOA, A. How long until the future. In: FLORES, M. A.; CARVALHO, A. A.; FERREIRA, F. I.; VILAÇA, M. T. (eds.). Back to the future: legacies, continuities and changes in educational policy, practice and research. Rotterdam: Sense Publishers, 2013. p. 29-38.

OLIVEIRA-FORMOSINHO, J. Desenvolvimento profissional dos professores. In: Formosinho, J. (coord.). Formação de professores: aprendizagem profissional e ação docente. Porto: Porto Editora, 2009. p. 221-284.

PILLEN, M.; BEIJAARD, D.; BROK, P. Tensions in beginning teachers' professional identity development, accompanying feelings and coping strategies. European Journal of Teacher Education, London, v. 36, n. 3, p. 240-260, 2013. https://doi.org/10.1080/02619768.2012.696192

PINHO, A. S.; ANDRADE, A. I. Redefining professional identity: the voice of a language teacher in a context of collaborative learning. European Journal of Teacher Education, London, v. 38, n. 1, p. 37-41, Apr. 2014. https://doi.org/10.1080/026197 68.2014.902440

PONTE, J. P.; CHAPMAN, O. Preservice mathematics teachers' knowledge and development. In: ENGLISH, L.; BUSSI, M. B.; JONES, G. A.; LESH, R. A.; SRIRAMAN, B.; TIROSH, D. (eds.). Handbook of international research in mathematics education. New York: Routledge, 2008. p. 223-261. 
PORTUGAL. Ministério da Educação. Decreto-lei n. 43, de 22 de fevereiro de 2007. Regime jurídico da habilitação profissional para a docência na educação pré-escolar e nos ensinos básico e secundário. Diário da República, Lisboa, 22 fev. 2007. Série I, n. 38, p. 1.320-1.328. Disponível em: https://dre.pt/application/conteudo/517819. Acesso em: 17 jan. 2020.

PORTUGAL. Ministério da Educação e Ciência. Decreto-lei n. 79, de 14 de maio de 2014. Regime jurídico da habilitação profissional para a docência na educação pré-escolar e nos ensinos básico e secundário. Diário da República, Lisboa, 14 maio 2014. Série I, n. 92, p. 2.819-2.828. Disponível em: https://dre.pt/application/ conteudo/25344769. Acesso em: 17 jan. 2020.

RODGERS, C. Defining reflection: another look at John Dewey and reflective thinking. Teachers College Record, Nova York, v. 104, n. 4, p. 842-866, June 2002.

RODGERS, C.; LABOSKEY, V. K. Reflective practice. In: LOUGHRAN, J.; HAMILTON, M. L. (eds.). International handbook of teacher education. Nova York: Springer, 2016. v. 2, p. 71-104.

RODGERS, C.; SCOTT, K.H.The development of the personal self and professional identity in learning to teach. In: COCHRAN-SMITH, M.; FEIMAN-NEMSER, S.; MCINTYRE, D. J. (eds.). Handbook of research on teacher education: enduring questions in changing contexts. New York: Routledge, 2008. p. 732-755.

RODRIGUES, F.; MOGARRO, M. J. Initial teacher education: a comparative study of two European higher education institutions. In: LEITE, L.; FLORES, M. A.; DOURADO, L.; VILAÇA, M. T.; MORGADO, S. (orgs.). ATEE Annual Conference 2014. Transitions in teacher education and professional identities. Braga: Instituto de Educação, Universidade do Minho, 2015. p. 395-404.

RODRIGUES, F.; MOGARRO, M. J. A construção da identidade profissional de uma futura professora: desafios e aprendizagens promovidos pela formação inicial. In: PINHAL, J.; CAVACO, C.; CARDONA, M.J.; COSTA, F.; MARQUES,J.; FARIA, R. (orgs.).Atas do XXIV Colóquio da AFIRSE Portugal. A escola: dinâmicas e atores. Lisboa: AFIRSE Portugal, Instituto de Educação da Universidade de Lisboa, 2018. p. 1.423-1.431.

SCHÖN, D. A. The reflective practitioner. New York: Basic Books, 1983.

SCHREIER, M. Qualitative content analysis in practice. London: Sage Publications, 2012.

SCHULTZ, K.; RAVITCH, S. Narratives of learning to teach: taking on professional identities. Journal of Teacher Education, Thousand Oaks, v. 64, n. 1, p. 35-46, 2013. https://doi.org/10.1177/0022487112458801

STENBERG, K. Identity work as a tool for promoting the professional development of student teachers. Reflective Practice, London, v. 11, n. 3, p. 331-346, June 2010. https://doi.org/10.1080/14623943.2010.490698

STENBERG, K.; KARLSSON, L.; PITKAMIEMI, H.; MAARANEN, K. Beginning student teachers' teacher identities bases in their practical theories. European Journal of Teacher Education, London, v. 37, n. 2, p. 204-219, Jan. 2014. https://doi.org/10.1 080/02619768.2014.882309 
SUTHERLAND, L.; HOWARD, S.; MARKAUSKAITE, L. Professional identity creation: examining the development of beginning preservice teachers' understanding of their work as teachers. Teaching and Teacher Education, London, v. 26, n. 3, p. 455-465, Apr. 2010. https://doi.org/10.1016/j.tate.2009.06.006

SUTHERLAND, L.; MARKAUSKAITE, L. Examining the role of authenticity in supporting the development of professional identity: an example from teacher education. Higher Education, Nova York, v. 64, p. 747-766, Apr. 2012. https://doi.org/10.1007/ s10734-012-9522-7

WARD, J. R.; MCCOTTER, S. S. Reflection as a visible outcome for preservice teachers. Teaching and Teacher Education, London, v. 20, n. 3, p. 243-257, Apr. 2004. https://doi.org/10.1016/j.tate.2004.02.004

\section{SOBRE AS AUTORAS}

Filomena Alves Rodrigues é doutora em educação pela Universidade de Lisboa (Portugal). Professora no Instituto Superior de Ciências Educativas (Portugal).

E-mail: filomenarodrigues@campus.ul.pt

Maria João Mogarro é doutora em educação pela Universidade de Lisboa (Portugal). Professora da mesma instituição.

E-mail: mjmogarro@ie.ulisboa.pt

Recebido em 25 de novembro de 2018 Aprovado em 27 de agosto de 2019 